\title{
AC 2010-1891: DEVELOPMENT OF THE REINVIGORATING ENGINEERING AND CHANGING HISTORY (REACH) PROGRAM: A COHORT EXPERIENCE FOR FIRST-TIME GRADUATE STUDENTS
}

\section{Monica Cox, Purdue University}

Monica F. Cox, Ph.D., is an Assistant Professor in the School of Engineering Education at Purdue University. She obtained a B.S. in mathematics from Spelman College, a M.S. in industrial engineering from the University of Alabama, and a Ph.D. in Leadership and Policy Studies from Peabody College of Vanderbilt University. Teaching interests relate to the professional development of graduate engineering students and to leadership, policy, and change in science, technology, engineering, and mathematics education. Primary research projects explore the preparation of engineering doctoral students for careers in academia and industry and the development of engineering education assessment tools. She is a NSF Faculty Early Career (CAREER) award winner and is a recipient of a Presidential Early Career Award for Scientists and Engineers (PECASE).

\section{Cyndi Lynch, Purdue University}

Cyndi Lynch is the Director of Fellowships and Graduate Student Professional Development in the Graduate School. Cyndi is a registered veterinary technician, focusing on animal behavior. She holds a bachelors degree in Animal Science and a Master of Science degree in Curriculum and Instruction from Purdue University. Research interests focus on doctoral student engagement in identified best practices, including mentoring and faculty-student relationships, orientations and transition courses, and doctoral student professional development. Her research explores the impact of best practices on the associated doctoral student learning outcomes and assessment of best practices. She instructs Purdue's Preparing Future Faculty course and the Preparing Future Professionals course, designed to facilitate graduate students transition into faculty positions and non-academic positions respectively.

\section{Jiabin Zhu, Purdue University, West Lafayette}

Jiabin Zhu is a PhD student in the School of Engineering Education at Purdue University. She obtained a B.S. in Physics from East China Normal University, a M.S. in Optics from Chinese Academy of Sciences, and a second M.S. in Biomedical Engineering from Purdue University. Her primary research interests relate to the professional development and mentoring of engineering graduate students. She is a student member of American Society for Engineering Education (ASEE).

\section{Phillip Dunston, Purdue University}

Phillip S. Dunston, Ph.D., is an Associate Professor in the School of Civil Engineering at Purdue University. He obtained his degrees (B.S., M.S., and Ph.D.) in civil engineering from North Carolina State University and then joined the Civil and Environmental Engineering faculty at the University of Washington for a number of years before moving to Purdue. His primary research activities involve the application of Virtual Reality visualization technologies to design processes, construction tasks, and training. Concurrently, he has maintained participation in activities to stimulate the pipeline of minority students pursuing higher education in engineering. He is also a past NSF Faculty Early Career (CAREER) award winner.

\section{Audeen Fentiman, Purdue University}

Audeen W. Fentiman is the Associate Dean of Engineering for Graduate Education and Interdisciplinary Programs at Purdue University. She is a Professor of Nuclear Engineering and holds courtesy appointments in the School of Engineering Education and the Division of Environmental and Ecological Engineering. Dr. Fentiman holds BS and MA degrees in Mathematics and MS and Ph.D. degrees in Nuclear Engineering, with the latter two degrees being 
from Ohio State University. Her teaching and research interests include radioactive waste management, engineering education, and environmental engineering risk assessment.

\section{Pamella Shaw, Purdue University}

Pamella Dale Shaw is the Associate Dean for Diversity, Equity, and Inclusion at Indiana University School of Dentistry. She also serves as the Statewide Director of the Louis Stokes Alliance for Minority Participation (LSAMP) in Indiana. LSAMP Indiana is a National Science Foundation program that works to increase the number of undergraduate underrepresented minority students receiving degrees in science, technology, engineering, and mathematics. The alliance includes eight universities, providing a variety of programs for students. Shaw is a native of Gary, Indiana, and received her bachelor's degree from Purdue University. She later graduated from the University of Kentucky with a Doctor of Dental Medicine and a Master's in Public Health. Shaw began her professional career in higher education at the University of Kentucky Medical Center as its Community Liaison for Health Professions and later became the Director of Health Careers Programs. She also joined the College of Dentistry as an adjunct faculty member in 1992. For over twenty-two years, she has worked with federal and state supported programs to help increase the success of students pursuing STEM degree and health professional careers in medicine, dentistry, pharmacy, and cancer research.

\section{Demetra Evangelou, Purdue University}

Demetra Evangelou is an Assistant Professor in Engineering Education at Purdue University, College of Engineering. Her research interests include early engineering and the effects of multiple influences on engineering thinking. 


\title{
Development of the Reinvigorating Engineering and Changing History (REACH) Program: A Cohort Experience for First-Time Graduate Students
}

\begin{abstract}
In 2009, the Reinvigorating Engineering and Changing History (REACH) Scholars Program was developed at a Midwestern University to offer qualified Master's and direct Ph.D. engineering students opportunities to explore multiple academic pathways and to work closely with their peers and with faculty to create a community of scholars who will be prepared broadly for careers across multiple domains. Informed from research, a central feature of the REACH Scholars Program is the use of a multiple apprenticeship model consisting of five features (intentionality; multiple relationships; collective responsibility; recognition; and respect, trust, and reciprocity) in which mentors will introduce Scholars to the engineering community and will provide them with a variety of perspectives to help them succeed as Scholars. The implementation of these five tenets enhances the professional development of Scholars via intentionally establishing multiple mentoring relationships within a collaborative learning environment. Other features of the program include Scholar participation in professional development workshops and seminars; engagement in research and grant writing groups; collaboration with existing campus programs to create sustainable communities across diverse graduate student populations; and the development of research skills. This paper provides an overview of the program and research questions that are being explored via the participation of students and mentors in the program.

\section{Project Objectives and Plans}

The Reinvigorating Engineering and Changing History (REACH) Scholars Program offers qualified Master's and direct Ph.D. engineering students opportunities to explore multiple academic pathways and to work closely with their peers, with alumni, and with faculty to create a community of scholars who will be prepared broadly for careers across multiple domains. Several aspects of this program have been informed by internal interviews with current graduate students, faculty, and administrators and by research identifying components that are most likely to promote student success within graduate engineering programs.
\end{abstract}

Findings from interviews with stakeholders provided much insight into challenges facing many domestic engineering students entering their first year of graduate school. First, many domestic graduate students have difficulty transitioning from undergraduate programs to graduate engineering programs. This is particularly true for students graduating from colleges and universities located in urban environments, for students graduating from minority-serving institutions or predominantly undergraduate institutions, or for students whose undergraduate academic programs were not as rigorous as those offered elsewhere. Second, many domestic students who enroll in a Master's program are not offered funding during their first semester. Reasons for this include previously enrolled graduate students garnering prime research assistantships, higher funding priorities being given to engineering Ph.D. students, and a preference for many engineering faculty to work with international students whose technical skills may be more developed at their time of enrollment than the skills of domestic students. Finally, students reported the lack of community present for graduate engineering students when 
compared to their undergraduate experiences. Although initial College and departmental graduate recruitment efforts target all domestic and underrepresented students before students are admitted, once students enroll, they are expected to form their own academic and social groups or to participate in larger groups targeted toward the general graduate student population. This informal formation of groups creates an added burden to students who have to face many of the challenges listed above.

Additional challenges confronting our targeted population, as determined by policy makers and self-reported by a national sample of doctoral students ${ }^{1}$, include the narrow disciplinary training of graduate students; ${ }^{2,3}$ graduate students' lack of training for jobs outside of academia; ${ }^{3}$ graduate students not being prepared for a changing society and academy; ${ }^{4,5}$ and declining enrollments of domestic students within doctoral engineering programs. Brown ${ }^{6}$ further explores challenges facing minority students by reporting that within engineering disciplines, minority students, without adequate funding, are less likely than other groups to complete their doctoral degrees in a timely manner. These students also are less likely to obtain a research assistantship (RA) during their graduate experiences ${ }^{7}$. Hypothesizing a positive correlation between acquisition of an RA and Ph.D. degree completion, Brown ${ }^{6}$ and Nettles and Millett ${ }^{7}$ recommend that underrepresented students be appointed RAs so that they can engage with faculty mentors and can acclimate into an academic community via their publishing and research collaborations. Other hindrances to underrepresented students entering advanced engineering programs and pursuing academic careers in engineering may be a lack of exposure to science and an absence of minority role models ${ }^{6}$.

Based on the challenges stated above, the overarching goals of the REACH program are to help students transition from undergraduate programs to graduate engineering programs and to inform Scholars about transition options after they obtain their Master's or Ph.D. degrees. More specifically, the goals of the REACH program include the following:

- To increase the number of undergraduate domestic students (particularly from underrepresented groups) who enroll in and graduate from M.S. and Ph.D. programs at the university.

- To increase the number of REACH Scholars who pursue Ph.D.s in engineering.

- To increase the number and quality of mentoring relationships in which REACH Scholars engage during their graduate careers.

- To improve professional development opportunities for REACH Scholars.

- To build and to enhance scholarly communities across Schools and the university.

\section{Significance of Project and Rationale}

The goals of the REACH Scholars program are met in several ways. First, recruitment occurs through existing and new partnerships with individuals and organizations. Second, faculty members within the College of Engineering and departmental research advisors will guide students toward acquiring their M.S. degrees and the possible pursuit of their Ph.D.s. Finally, PIs build and enhance scholarly communities and will develop strategies for sustaining the REACH Scholars model within the College of Engineering and will work with support services and other staff and colleagues to provide professional development opportunities and mentoring relationships for Scholars. 


\section{Recruitment Plan and Scholar Selection}

The REACH Scholars program collaborates with existing national recruitment efforts and university initiatives to recruit the targeted populations. Development of a strategic communications plan, complete with electronic and print marketing materials (brochures, webpages, e-promotions) for dissemination through a variety of existing recruitment activities is a key component of accomplishing REACH program goals. An important distinction of this program is that students also will be recruited intentionally from a broader variety of disciplines (e.g., chemistry, mathematics, biology, computer science, and physics) than just those represented by undergraduate engineering programs, since these majors can provide solid foundations for study in many graduate engineering disciplines. Potential students are recruited at graduate school fairs and via partnerships with liberal arts colleges with strong science programs, Ivy League universities, minority-serving institutions, primarily undergraduate institutions, and private organizations with commitments to increasing the number of domestic students pursuing advanced degrees in STEM fields.

The REACH Scholars program requests nominations from engineering graduate programs during the admission process. The REACH PIs review admission applications and select recipients based on the contribution to diversity of the REACH Scholars program and to their potential to succeed as leaders in their fields. Information reviewed includes items such as undergraduate institution, previous work or research experiences, leadership, and potential to contribute to the goals of the REACH Scholars program.

\section{REACH Scholars Support Services and Programs}

The REACH Scholars program collaborates with existing institutional support services focused on the categories of professional development, writing, research, computing, and community. Additional support services through professional development include individual career consultations and career planning guides. Writing support services include resources on teaching, styles guides, and grammar and mechanics. Library services conduct workshops on database searching, using reference management software, and research guides. The Office of the Vice President for Research sponsors proposal writing workshops. Computing support services include workshops, tutorials, and online guides for course management programs, instructional design and development, library research technology, and research computing services. Statistical consulting and design services are provided through the university, which focuses services on measurement and assessment, psychometrics, and educational and behavioral sciences empirical research. Community support services that encourage academic and social integration include graduate student groups focused on cultural communities such as AfricanAmericans, Latinos, and Native Americans.

Informed from research, a central feature of the REACH Scholars Program is the use of a multiple apprenticeship model consisting of five features (intentionality; multiple relationships; collective responsibility; recognition; and respect, trust, and reciprocity) in which mentors will introduce Scholars to the engineering community and will provide them with a variety of perspectives to help them succeed as Scholars ${ }^{8}$. The implementation of these five tenets enhances 
the professional development of Scholars via intentionally establishing multiple mentoring relationships within a collaborative learning environment. It is expected that students' participation in these activities will foster the development of well-rounded Scholars who complete their degrees and form long-lasting engineering networks beyond the university.

Intentionality is defined as faculty with scholarly and professional expertise helping students self-reflect upon the process of creating scholarly ideas and communicating them to others in their field. REACH Activities that support the tenet of Intentionality include monthly REACH seminars. The outcomes of the seminar focus on three main areas: (1) peer mentoring through discussion of daily activities, coursework, research, and other topics, (2) a professional development component focused on skill development and strategies that enhance their career development, (3) feedback back from REACH PIs on options.

Multiple relationships, the second tenet of the REACH Scholars' multiple apprenticeship model, focuses on student engagement with numerous intellectual mentors. In addition to the student advisor relationship, central to the graduate education experience, REACH Scholars actively seek and develop multiple relationships with REACH PIs, advanced graduate students, faculty mentors, and alumni mentors. A mentoring network is formed. REACH Scholars are then able to tap into the expertise of anyone within their network to develop an essential professional skill.

Collective responsibility, the third tenet, is where all parties share responsibility for the development of students' learning. Members of the REACH "family" hold each other responsible for program success. Faculty across the College and University engage in conversations with and about REACH Scholars.

Recognition is an important component in successful mentoring relationships. This tenet allows individuals to learn mentoring techniques and to be recognized and rewarded for demonstrating these techniques. Students formally learn how to mentor and then practice these techniques during the second year of the program. All mentors are recognized and rewarded for their contributions to the REACH program.

Respect, trust, and reciprocity encompass the final tenet. Within a community, individual differences are taken into consideration and are acknowledged. Students recognize and discuss academic and industrial cultures and understand how to succeed within these environments. Students work with a cohort of diverse students during their Purdue graduate experience. Some activities within the community are:

(1) Student Meetings. Scholars will engage in informal meetings where they will discuss academic (e.g., academic success strategies, adjusting to the university and to graduate school, library resources) and social (e.g., forming a support group) issues. Scholars will be grouped into cohorts and will be expected to collaborate with members of their cohorts throughout their experiences at the university.

(2) Professional Development Workshops and Seminars. Outside speakers and experts will be invited to present workshops and seminars for Scholars. Sample topics include reasons for pursuing a Ph.D., opportunities for M.S. and Ph.D. students in academic and nonacademic settings, selecting a thesis topic, and applying for federal fellowships. 
(3) Mentoring Networks. Scholars make connections to College of Engineering faculty, Purdue alumni, Graduate School staff and incoming graduate students. Through the mentoring networks, Scholars develop strategies for succeeding in graduate school, engaging in graduate research, attending professional conferences, enhancing professional skills, and identifying various career options. Mentors provide success strategies for students based upon their backgrounds.

(4) Scholar Mentors. Within the first year of the program, Scholars become acclimated to the university, but in year two, Scholars become mentors to newly admitted Scholars, assist in the organization of programs and activities for the program, and serve as liaisons in their respective schools.

(5) Research and Grant Writing Groups. Dissertation boot camps, dissertation support groups and dissertation coaches are services employed to aid doctoral students in completing that final written product by developing writing strategies and organize vast amounts of literature and data. (6) Development of Campus-wide Activities. Tapping into existing programs at the university and encouraging Scholars to demonstrate leadership, PIs encourage Scholars to partner with existing programs (e.g., AGEP, WIEP, or GEM) within at least one campus-wide activity annually that can provide information to undergraduate students about graduate school or can explore ways that sustainable communities can be formed across diverse graduate student populations at the university.

(7) Development of Research Skills. Scholars will develop additional support structures via their interactions with research advisors who are funding their $25 \%$ appointments. Students will be able to apply for additional funding that will help to fund partially their attendance at academic conferences in which they can present their research or engage in professional development activities that align with the mission of the REACH program.

(8) Sharing of Academic Resources. In addition to networking, Scholars will be encouraged to participate in a resource donation program in which graduating students may share notes, text references, and other resources with incoming students and where students within similar schools might create a repository of professional development and course-related resources.

\section{Assessment and Evaluation}

In addition to using basic metrics related to the goals described earlier in the proposal, the team will use a logic model to assess the overall impact of the REACH program ${ }^{9}$. More specifically, we will examine outputs (e.g., student publications of their research, activities that impact the larger student population); intermediate outputs (e.g., students' gaining awareness of doctoral opportunities in engineering); and ultimate outputs (e.g., students enrolling within doctoral engineering programs after participation in the REACH program) within the program. Also, both formative and summative assessments of the program and its stakeholders (e.g., Scholars and Mentors) will occur in addition to longitudinal tracking of the students within their respective programs. Formative assessments will be used to confirm the effectiveness of the program, and the Advisory Board will provide another mechanism for assessing REACH annually and at the end of the project. Data about successful features of the program will be disseminated across the schools so they may implement similar efforts within their programs.

Engineering education research will also be a major component of this program and will provide first-hand understanding about the experiences of students within the program. Using career theories as a theoretical framework and Scholars as a test bed, the PI will work closely with 
Scholars to understand how domestic graduate engineering students are being socialized within the College of Engineering. Sample research questions include the following:

- To what extent does the REACH program help students to embrace the norms of the engineering profession?

- What elements of the REACH program are most beneficial for preparing graduate students for careers in academia, government, and industry?

A mixed methods research design will be used to evaluate the extent to which students within the REACH program are benefitting from specific program elements such as mentoring and the creation of peer social networks. To note the impact of formal program elements upon REACH Scholars, surveys and one-on-one interviews will be used to understand the experiences of REACH Scholars in terms of their mentoring experiences, their learning experiences with respect to professional skills, and their adaption to the College of Engineering as a community. This research will be conducted longitudinally to examine the long-term impact of the program upon students who enter diverse fields of study. Findings will be distributed at conferences and within peer-reviewed journals with readership interested in the impact of projects such as the one described.

\section{Conclusions}

In addition to the activities mentioned above, the REACH Scholars program is different for several reasons. First, it focuses strongly upon the retention of students in graduate education and students' progressions to doctoral studies. As such, activities are designed in a way that will increase the diversification of engineering across a variety of sectors. Second, it draws upon the expertise and the experiences of the PI team, with perspectives from various levels and disciplines within the Graduate School and the College of Engineering. By including individuals with different perspectives in the administration of the program, students in the cohort engage with people who they might not meet in their home departments. Finally, the program has the potential to serve as a model for other graduate programs that are trying to engage their Masters and $\mathrm{Ph}$.D. students in cohort experiences during their graduate careers. Via REACH assessment efforts, benefits of such experiences might be identified for first-time graduate students.

\section{Acknowledgement}

This material is based upon work supported by the National Science Foundation under Grant No. 0850199.

\section{Bibliography}

1. Nerad, M., \& Cerny, J. (2000). From rumors to factors: Career outcomes of English Ph.D.s. ADE Bulletin, 124, 43-55.

2. Committee on Science, Engineering, and Public Policy (COSEPUP) of the National Academy of Sciences, The National Academy of Engineering, and the Institute of Medicine. (1995). Reshaping the graduate education of scientists and engineers. Washington, DC: National Academy Press.

3. Nerad, M. (2004). The Ph.D. in the U.S.: Criticisms, facts, and remedies. Higher Education Policy, 17, 2, 183199.

4.Nyquist, J. D., Abbott, R. D., \& Wulff, D. H. (Eds.). (1989). Teaching assistant training in the 1990s. New

Directions for Teaching and Learning, No. 39. San Francisco: Jossey-Bass. 
5. Nyquist, J. D., Austin, A. E., Sprague, J., \& Wulff, D. H. (2001). The development of graduate students as teaching scholars: A four-year longitudinal study (Final Report, Grant \#199600142). Seattle: University of Washington, Center for Instructional Development and Research.

6. Brown, S. V. (2000). The preparation of minorities for academic careers in science and engineering. In G.

Campbell, R. Denes, \& C. Morrison (Eds.), Access denied: Race, ethnicity, and the scientific enterprise (pp. 239268). New York: Oxford University Press.

7. Nettles, M.T., \& Millett, C.M. (2006). Three magic letters: Getting to Ph.D. Baltimore: The Johns Hopkins University Press.

8. Walker, G.E., Golde, C.M., Jones, L., Bueschel, A.C., \& Hutchins, P. (2008). The Formation of scholars:

Rethinking doctoral education for the twenty-first century. San Francisco: Jossey-Bass.

9. Committee on Evaluating the Efficiency of Research and Development Programs at the U.S. Environmental Protection Agency, National Research Council. (2008). Evaluating Research Efficiency in the U.S. Environmental Protection Agency. Washington, DC: National Academy Press. 